\title{
SEISMIC ANALYIS OF CONCRETE ARCH DAMS - TWO CASE STUDIES
}

\author{
N. Monteiro Azevedo ${ }^{1}$, J.V. Lemos ${ }^{1}$, D. Silva Matos ${ }^{2}$, José Paixão ${ }^{2}$
}

${ }^{1}$ Concrete Dams Department, LNEC - Laboratório Nacional de Engenharia Civil, Lisboa, Portugal (nazevedo@lnec.pt, vlemos@lnec.pt)

${ }^{2}$ Direcção de Projectos e Investimentos - Barragens, EDP - Gestão da Produção de Energia S.A., Porto, Portugal (domingossilva.matos@edp.pt, josé.paixao@edp.pt)

\begin{abstract}
In the framework of the Portuguese National Programme for Dams with High Hydroelectric Potential (PNBEPH), a set of large concrete dams is currently under design or construction, including several $100 \mathrm{~m}$ high arch dams. Earthquake loading is one of the important aspects to be considered in the design of these structures. A variety of numerical methods have been developed over the years by various researchers and are presently available for seismic analysis of concrete dams. The methods in use by the dam engineering community have different approaches, for example, in the representation of the seismic action, the dam-water interaction or the structural nonlinear behavior. In the paper, the models applied in the study of new Portuguese dams are presented, and their fundamental assumptions discussed. In particular, the analysis of the response of arch dams to the Maximum Design Earthquake is examined, considering the non-elastic behavior of the contraction joints and the dam foundation. An explicit time integration algorithm was used in these simulations, allowing a detailed representation of the slip and separation events along the discontinuities. The boundary conditions appropriate for seismic analysis are discussed, namely the type of free-field boundaries employed. In the paper, the application of this modeling methodology to two new dams is presented and discussed. Foz Tua dam, that is already under construction, is a concrete arch dam, $108 \mathrm{~m}$ high and $275 \mathrm{~m}$ long at the crest. Fridão dam is also a concrete arch dam, $98 \mathrm{~m}$ high and with a crest length of $300 \mathrm{~m}$. Design criteria and the results of the numerical analyses are discussed.
\end{abstract}

Keywords: Concrete arch dam, Earthquake analysis, Design criteria.

\section{INTRODUCTION}

The analysis of the response of large arch dams to earthquake involves several computational problems, given the complexity of the system composed of the concrete structure, the water reservoir and the rock mass foundation. The contraction joints that separate the cantilevers blocks that constitute the concrete vault have no tensile strength, so their opening under intense seismic action has to be taken into account. Non-elastic behavior may also arise at the 
dam-rock interface or along the rock mass discontinuities, or by cracking of the concrete. In the work reported in this paper, a general numerical framework, based on a deformable block discrete element approach, is used to represent the system [1]. The dynamic analysis is performed by means of an explicit time stepping algorithm. The seismic input is applied at the model base, represented by a non-reflecting boundary formulation; free-field meshes are used to provide dynamic boundary conditions at the model sides. Various models are available to represent the hydrodynamic interaction between dam and fluid (e.g. [2]). The classical addedmass approach is used here, given its sufficient accuracy and computational advantages for explicit algorithms.

In the paper, the essential aspects of the numerical model are presented, as well as the results of its application to two large dams recently designed in Portugal, which are introduced in the next section.

\section{FOZ TUA AND FRIDÃO HYDROELECTRIC PROJECTS}

At present, EDP, Energias de Portugal S.A., has under construction three new hydroelectric projects - namely Baixo Sabor, Ribeiradio-Ermida and Foz Tua Projects. EDP has also under construction three new powerhouses - Venda Nova III, Salamonde II and Alqueva II. All these projects, with a total power of about $2.000 \mathrm{MW}$, will increase the renewable production of electricity in Portugal, and the last ones will also contribute to a more flexible exploitation of EDP electric generation. In the framework of the Portuguese "National Program of Dams with High Hydroelectric Potential" (dated of December 2007) the Foz Tua Project was the first one to be launched and its construction started in April 2011.

The Foz Tua Hydroelectric Project [3] is located in the north region of Portugal, in the Tua River, an important right bank tributary of Douro River, close to its confluence into Douro River. The project includes a double curvature arch dam, which is $108 \mathrm{~m}$ high and is provided with a controlled surface spillway over its crest designed for a $5500 \mathrm{~m}^{3} / \mathrm{s}$ flood, an hydraulic circuit in the right bank, about $700 \mathrm{~m}$ long, composed of two independent tunnels, and a downstream powerhouse equipped with two reversible units with a rated output of $131 \mathrm{MW}$ each one.
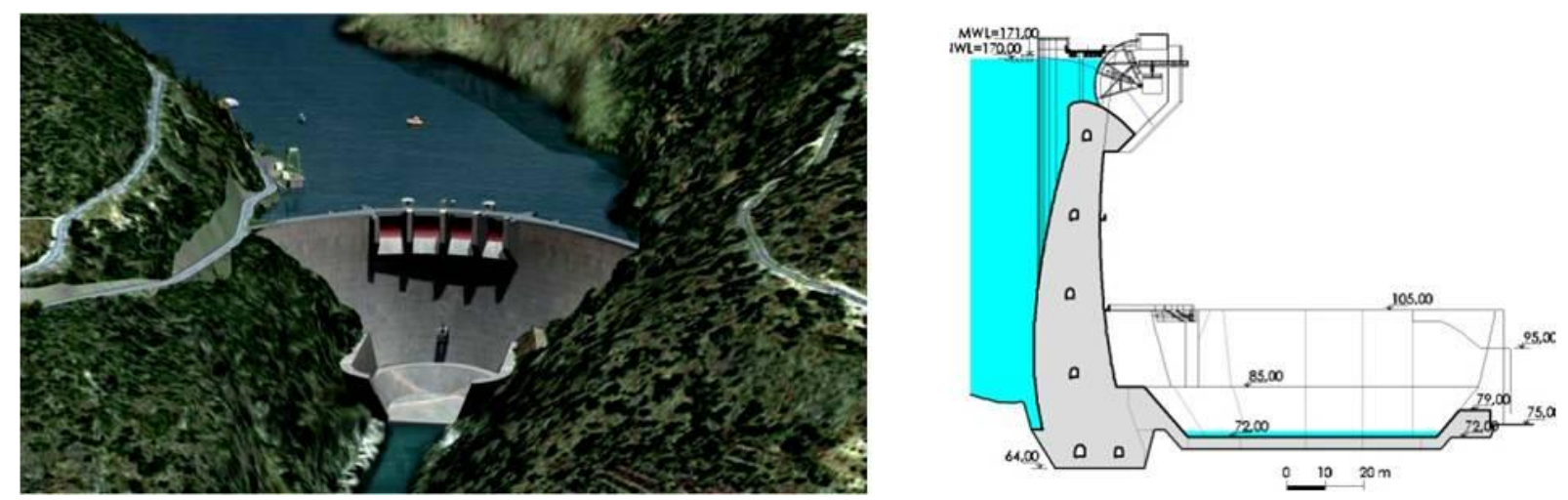

Figure 1. Foz Tua Hydroelectric Project. Preview and cross section of the dam. 
The designed arch dam has a total crest length of $275 \mathrm{~m}$, at elevation $172 \mathrm{~m}$. a.s.1., and a total concrete volume of $317000 \mathrm{~m}^{3}$ (Fig. 1). In the dam site, the valley is quite narrow and the rock foundation is sound granite. Downstream, close to the confluence with the Douro River, the valley becomes wider and schistous rocks are present. For the full storage level, located at elevation $170 \mathrm{~m}$. a.s.l., the reservoir capacity is 106 million cubic meters. The surface spillway is provided with four $15.7 \mathrm{~m}$ wide spans, controlled by radial gates, and a downstream plunge pool. The dam is also provided with a bottom outlet with a maximum discharge flow of $200 \mathrm{~m}^{3} / \mathrm{s}$. A diversion tunnel located in the left bank and two concrete gravity cofferdams allow the dam construction in the river bed zone.

The concession of the Fridão Hydroelectric Project [4] was also awarded to EDPEnergias de Portugal S.A. in the framework of the Portuguese "National Program of Dams with High Hydroelectric Potential" and its construction will start in the second half of 2012. It is located in the northwest region of Portugal, in the middle reach of Tâmega River, one of the most important right bank tributaries of Douro River.

The main dam is a concrete arch type with a maximum height of $98 \mathrm{~m}$, a crest length of $300 \mathrm{~m}$ and a total concrete volume of $251500 \mathrm{~m}^{3}$ (Fig. 2). The rock foundation is mainly composed of hornefels and aplite-pegmatites. A gated surface free fall spillway is incorporated over the central part of the dam body, with a design discharge capacity of $4000 \mathrm{~m}^{3} / \mathrm{s}$, as well as a bottom outlet designed for a $250 \mathrm{~m}^{3} / \mathrm{s}$ flow. The dam reservoir has a total storage capacity of 196 million cubic meters.

The underground hydraulic circuit, in the right bank is completely independent of the main dam, has a total length of about $380 \mathrm{~m}$ and a current concrete lined cross section with $10.5 \mathrm{~m}$ diameter. The shaft powerhouse is equipped with one non-reversible Francis turbine designed for a nominal $350 \mathrm{~m}^{3} / \mathrm{s}$ flow. The erection and command building and the compact switchyard are located in the access powerhouse surface platform, excavated in the hillside. The project also includes a downstream concrete gravity dam about $30 \mathrm{~m}$ high, located $4.2 \mathrm{~km}$ from the main dam.

As it can be seen in Figs. 1 and 2, Foz Tua dam and of the main dam of Fridão Project, are very similar structures. Fridão dam has a lower height dam Foz Tua (98 m against $108 \mathrm{~m}$ ), but lies in a wider valley, so its crest length is larger (300 m against $275 \mathrm{~m}$ ).
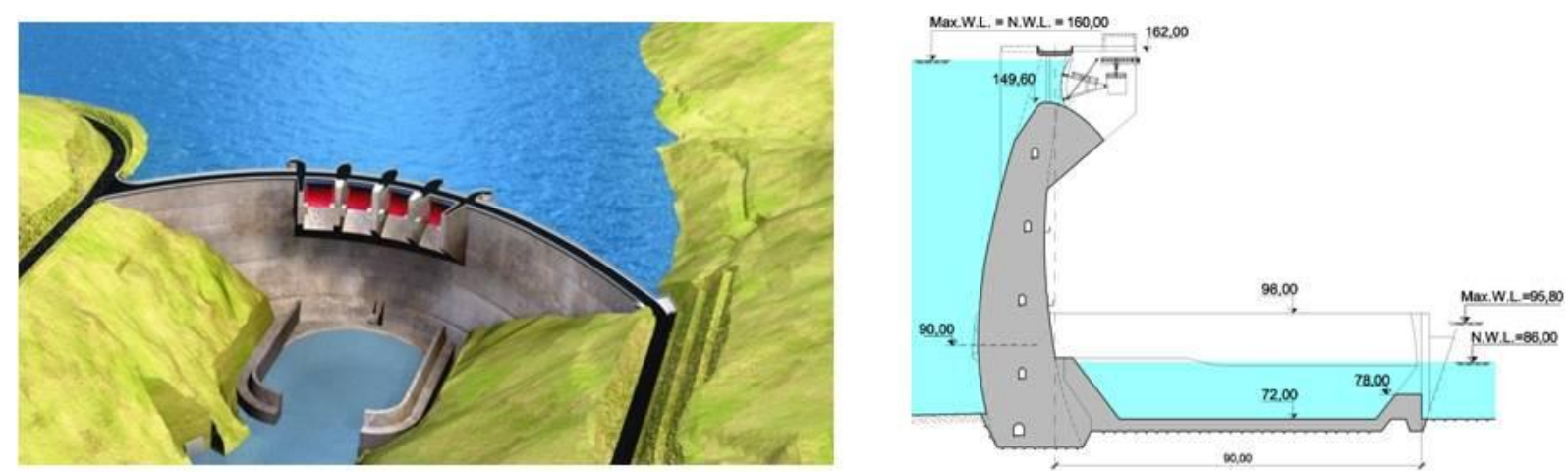

Figure 2. Fridão Hydroelectric Project. Preview and cross section of the dam. 


\section{DAM DESIGN SCENARIOS AND SEISMIC ACTIONS}

According to the Portuguese Regulations for Safety of Dams [5], and namely to the Portuguese Dam Design Recommendations (PDDR) [6], two types of scenarios have to be considered when checking the dam structural safety: the exploitation and the failure scenarios.

The most frequent actions that can load the dam structure have to be considered in the exploitation scenarios, as are the case of the concrete weight, hydrostatic pressure, thermal variations, foundation uplifts and others. The dam must be able to support these actions without (or with minor) damages. On the other hand, the failures scenarios deal with extreme actions that can cause important damages in the dam. As example of failures scenarios, ruptures along the dam foundation surface or along discontinuities in the dam foundation can be pointed out. For failure scenarios overall dam stability has to be assured and uncontrolled reservoir water release cannot occur.

Earthquake loading, due to seismic activity, is one of the important actions that have to be considered in the design of dams. In addition to a set of complete geological and geotechnical studies, seismic studies are essential in order to estimate the dynamic loadings that can load the dam. For these issues the statements of PDDR are very similar to the ICOLD (International Commission on Large Dams) standards.

The seismic studies are based mainly in the local and regional geological settings, and in the area seismic history. In this frame, the seismotectonic studies, which include the identification of the possible active faults, are a major issue.

The seismic action, which represents the level of the earthquake motion at the dam site, depends on the geological and tectonic conditions in the dam region, the localization of the earthquake source and, consequently, on the released energy, source mechanism, length of transmission path and related attenuation, and surface geology of the dam site.

In accordance with PDDR, the seismic studies should define the seismic actions in terms of intensity, frequency content and duration of the seismic vibrations in the dam site. The following design earthquakes types should be considered:

- The maximum credible earthquake (MCE) which must be evaluated using a deterministic procedure or a probabilistic approach, and should have a long return period;

- The maximum design earthquake (MDE) which for dams with high potential risk hazard should be considered as the MCE;

- The operating basis earthquake (OBE), less intensive than the MDE, and with an assumed return period related to the involved estimated risks, and that is determined by probabilistic approaches.

According to ICOLD [7], the OBE is an earthquake with significant probability of occurrence during the dam life, and it only can cause minor damage in the dam. So a $50 \%$ probability of not being exceeded in 100 years is usually adopted for OBE estimation. In this frame, and for dam design and for dam safety analysis, the OBE must be considered as an action included in the exploitation scenarios. In addition, a more severe earthquake with a return period of about 1000 years (BDE - Base Design Earthquake) is also used to check structural dam behavior in these scenarios. 
The MDE must be estimated rather by deterministic procedures taking into account local and regional seismotectonic conditions. Probabilistic approaches, considering long return periods, can also be applied for MDE estimation, and are often used for comparison purposes. So the MDE should be considered a failure scenario, concerning dam design or structural safety assessment purposes.

In addition, Reservoir-Induced-Earthquake (RIE) that represents the ground motions capable of being triggered at the dam site by the presence of the reservoir should be taken into account, and so, the effects of faults susceptible to give rise to induced seismicity should be properly evaluated. Depending on the dam location and on seismotectonic conditions the RIE may represent motions less than, equal to, or greater than the OBE, but should in no case be greater than the MDE [7].

Regarding the definition of the seismic actions in Foz Tua and Fridão dam sites $[3,4]$, the following studies have been performed:

- A geological and geotechnical study of the dam site and surround zone, based in site investigations and in "in-situ" and laboratorial tests, that have been performed by EDP;

- The geological mapping of the project site and of the reservoir area executed by FCUP - Faculdade de Ciências da Universidade do Porto (Sciences School of Oporto University);

- Seismological studies and definition of design earthquakes performed by LNEC.

In these seismological studies, LNEC made the estimation of the OBE and of the MDE using deterministic methods, but performed also a complementary estimation of the OBE by a probabilistic approach.

In the deterministic approaches, credible seismic scenarios have been previously defined using two parameters: the magnitude $(\mathrm{M})$ and distance $(\mathrm{R})$ between the earthquake focus and the dam site. For the defined scenarios the ground motion at the dam site have been evaluated both by the conventional empirical method, based on attenuation laws appropriate to the tectonics environment, and by a numerical method based on a stochastic model of fault rupture and seismic radiation (LNEC [8,9]).

\section{DESIGN OF THE ARCH DAMS}

The adopted shapes of the Foz Tua and Fridão arch dams have been defined by the Department of Dams of EDP, based on the experience developed for some decades in the design of this type of structures and continuously updated [3,4].

Preliminary design is usually based on the acquired experience and on the comparison with similar projects. In a second stage, shape definition is refined using finite element models and taking into account the main static and dynamic actions. Subsequently, a shape optimization process is usually carried out, in order to reduce the concrete dam volume enforcing an appropriate structural behavior.

The limit values of 5.5 and 1.0 MPa for the compression and tensile stresses, respectively, were considered in the following loading scenarios: construction phase and reservoir filled up to the normal water level, with and without winter thermal action. The corresponding values for the scenario of empty reservoir in the summer period were 7.0 and 1.5 MPa. The limit values of 0.80 and 0.95 were adopted for the ratio between the tangential and normal forces at 
the base of each dam block for the scenario of reservoir filled up to the normal water level, respectively with and without winter thermal action, and taking into account the uplift pressures. Afterwards, a final checking of the structural behavior of the dam for all the mandatory scenarios according to Portuguese regulations on dams was performed.

The detailed structural behavior of the dam-foundation structure was foreseen by 3D finite element analyses (performed with the Ansys software). The relevant load combinations for exploitation scenarios, considered according to the Portuguese Regulation requirements, comprise the dead weight of the independent dam blocks along construction $\left(\gamma=24 \mathrm{kN} / \mathrm{m}^{3}\right)$, the hydrostatic pressure $\left(\gamma=10 \mathrm{kN} / \mathrm{m}^{3}\right)$ at the upstream face for characteristic water table levels of the exploration of the reservoir, the extremes of the seasonal variations of temperature occurring in the structure, with respect to the reference thermal field occurring at the date of the grouting of the contraction joints, and the basis design earthquake (BDE). The concrete and foundation mass were considered as isotropic, linear elastic materials with the values $\mathrm{E}=$ $20 \mathrm{GPa}, v=0.2$ and $\alpha=10^{-5} \mathrm{C}^{-1}$ for the mechanical proprieties.

Considering as an example the Foz Tua dam, the structural behavior of dam agrees in general terms with the above limits prescribed in the optimization phase. It is pointed out that, as a result of this phase, for several load combinations the extreme values of the prescribed stresses occur in vast zones, showing a good exploitation of the structural material. The evaluated behavior for the several scenarios comprising the BDE seismic action, which was defined by a response spectra based in the Portuguese Regulation and a $0.084 \mathrm{~g}$ peak ground acceleration (return period of 949 years), is completely suitable presenting 1.7 MPa tensile stresses (close to the concrete cracking level) and 7.0 MPa compression stresses.

\section{ANALYSIS OF DAMS SUBJECT TO THE MAXIMUM DESIGN EARTHQUAKE}

\subsection{Numerical models}

The analysis of the dynamic behavior of the two arch dams was performed with the code 3DEC [10], a discrete element program employed initially in rock mechanics, but currently also applied in the study of many types of structures with discontinuities. In both models reported, the rock mass was assumed elastic, given its quality, and thus the nonlinear behavior of the foundation was restricted to the dam-rock interface. The concrete arch was represented by a set of elastic cantilever blocks separated by the vertical contraction joints. Each dam block, as well as the foundation block, are discretized into finite elements.

The seismic analysis of problems involving foundations with nonlinear behavior may be approached with the type of numerical model shown in Fig. 3, in which the seismic action is represented by plane waves, propagating upwards from a model base which was assigned non-reflecting character, using a viscous boundary formulation. The dynamic boundary conditions of the 4 lateral boundaries of the model are obtained by performing independent freefield calculations, subject to the same base motion. For each side of the model, a 2D free-field mesh is created, each one having its own 1D free-field meshes at the sides [1]. The dynamic analysis procedure employs an explicit, central-difference algorithm. 
In the present studies, the only discontinuities are the dam-rock interface and the contraction joints, but this scheme can also handle models with rock mass joints, so that potential wedge failure mechanism may be assessed.

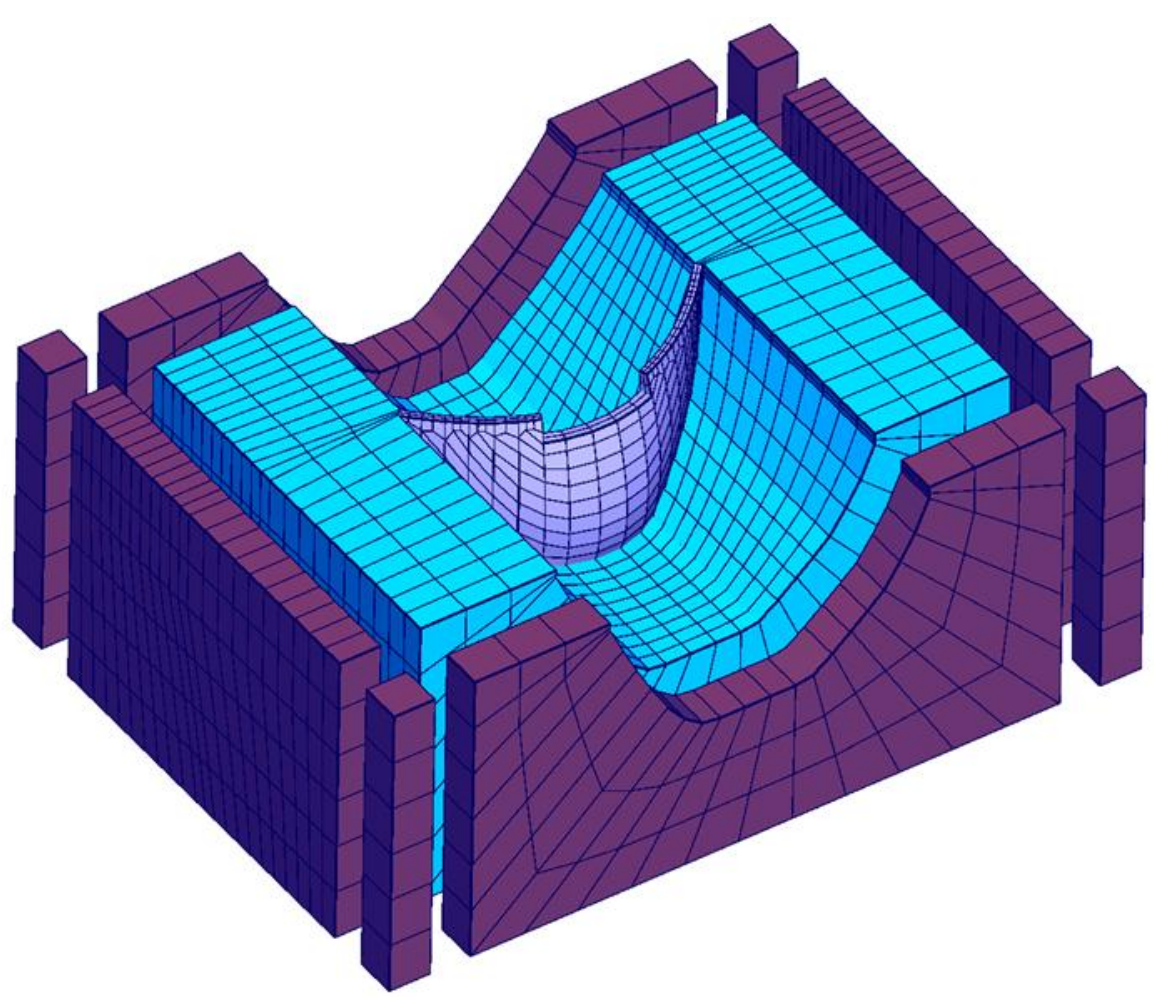

Figure 3. Numerical model for seismic analysis of Foz Tua dam. Main model and free-field meshes.

The 3DEC model in Fig. 3 shows the case of Foz Tua dam. The meshes of the dam blocks and the foundation rock mass are composed of 20-node brick finite elements. The discontinuities were assumed to obey a Mohr-Coulomb criterion. The dam-rock interface was assigned a tensile strength of $3 \mathrm{MPa}$, a cohesion of $4.7 \mathrm{MPa}$ and a friction angle of $55^{\circ}$. The contraction joints were assumed to have only frictional strength, with an angle of $45^{\circ}$, therefore neglecting the effect of the shear keys. Mass-proportional Rayleigh damping was used for the concrete structure with a value of $5 \%$ at the fundamental frequency of the dam. No damping was applied in the rock mass elements. The hydrodynamic interaction effects were represented by Westergaard added-masses.

The seismic action was represented by 2 components, in the upstream-downstream and vertical directions, both applied as stress records at the non-reflecting bases of the model and the free-field meshes. The seismological studies of Foz Tua led to a MDE of $0.27 \mathrm{~g}$ [8]. Accelerograms at the dam site were generated by a numerical stochastic fault rupture calculation. Several combinations of records were used, with the vertical component scaled by a factor of $2 / 3$. One of the records employed is shown in Fig. 5.

For Fridão dam, a lower value of PGA, 0.14g, was prescribed in the seismological studies, which also provided a set of records for the structural analysis [9]. 


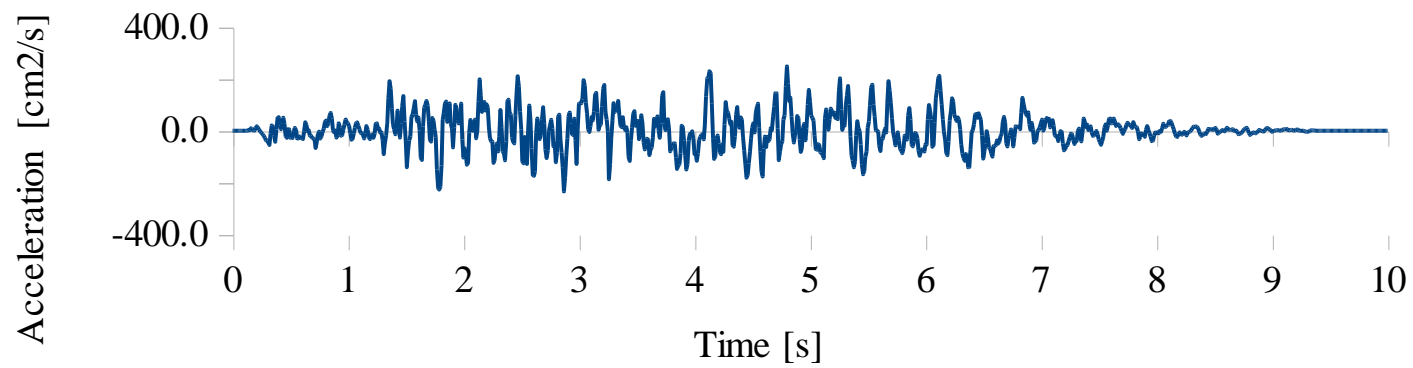

Figure 4. Accelerogram for MDE analysis of Foz Tua dam (PGA=0.269g).

\subsection{Analysis of results - Foz Tua dam}

Prior to the nonlinear calculations, modal analysis of Foz Tua dam were performed, using the same mesh for the structure, but assuming an elastic massless foundation. For the full reservoir situation, the two lowest frequencies were: $2.7 \mathrm{~Hz}$, for the asymmetric mode, and $3.2 \mathrm{~Hz}$, for the symmetric mode, both shown in Fig. 5.

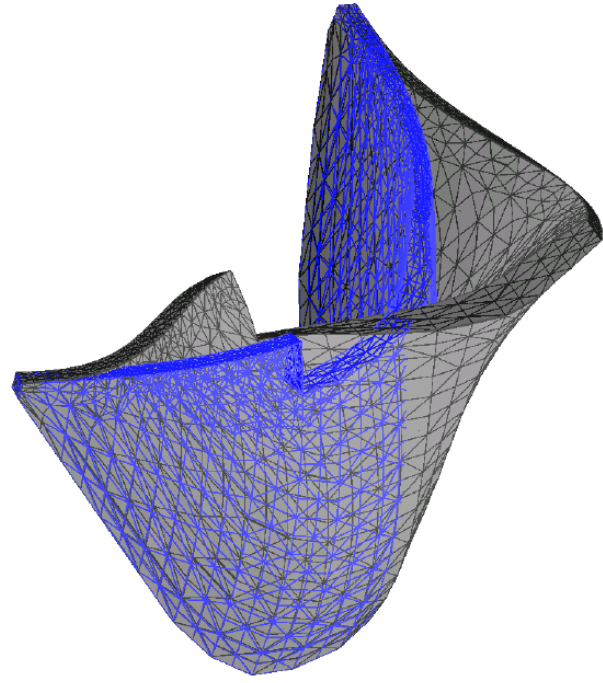

(a) mode $1(2.7 \mathrm{~Hz})$

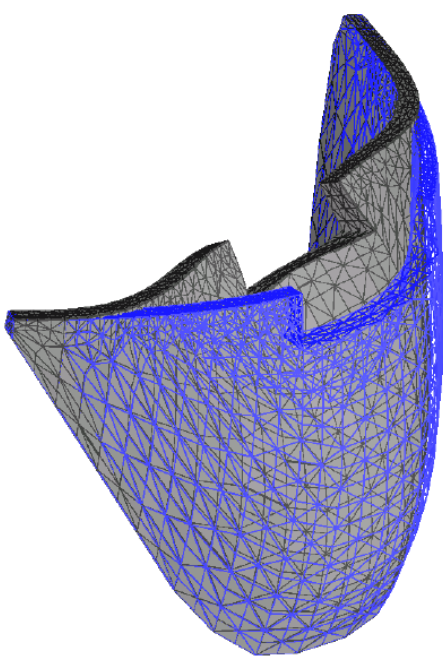

(b) mode $2(3.2 \mathrm{~Hz})$

Figure 5. Modal shapes for the two lowest frequencies, Foz Tua dam.

For the MDE, several simulations with different seismic actions were performed, considering various input records for horizontal (upstream-downstream) and vertical motions. For each case, elastic and non-elastic analyses were conducted, but only the latter results, for full reservoir conditions, will be presented. Fig. 6 shows the history of upstream-downstream displacement at the dam crest in one of the nonlinear runs, displaying a peak of about $50 \mathrm{~mm}$. The peak stresses obtained for the various records were in the same range. In the nonlinear analyses, the peak compression in the arches, developing in the central sections of the upper arches, ranged from 7 to $8.6 \mathrm{MPa}$. Fig. 7 shows an envelope of peak compressive stresses in the arches, in the upstream and downstream faces. Arch tensile stresses were not significant in 
the nonlinear runs due to the opening of the contraction joints. In the cantilevers, maximum compressive stresses reached $6 \mathrm{MPa}$, and tensile stress peaks ranged from 2.2 to $2.7 \mathrm{MPa}$, as shown in Fig. 8. Compressive stresses are well within the admissible range for the dam concrete, while tensile stress results indicate that significant cracking in the dam body is not to be expected. Therefore the assumption of elastic cantilevers is acceptable.

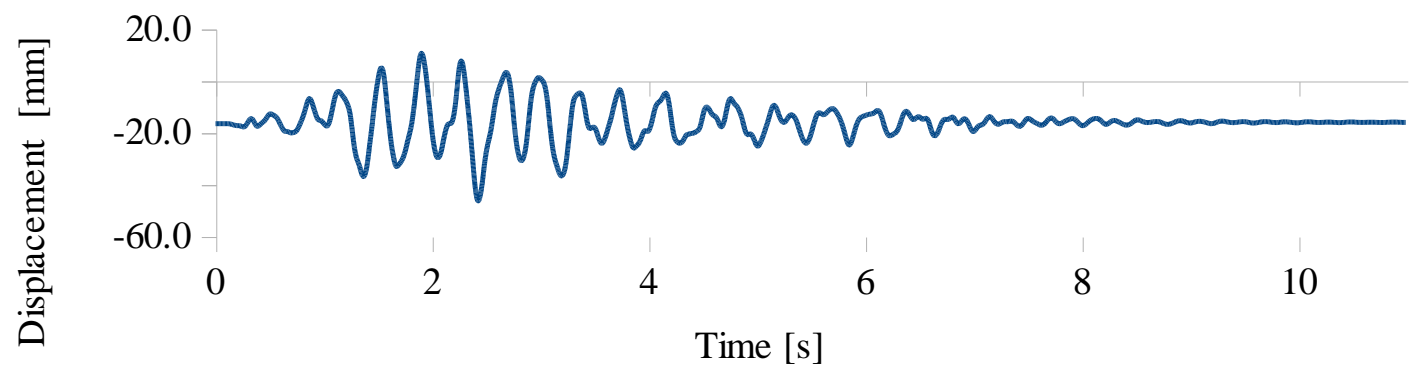

Figure 6. Horizontal displacement at crest, Foz Tua dam.

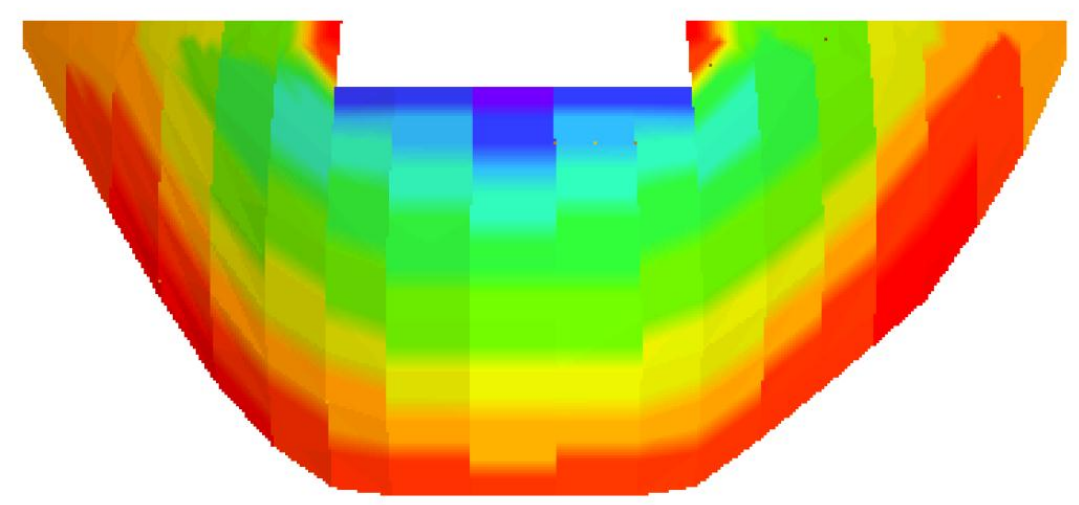

(a)

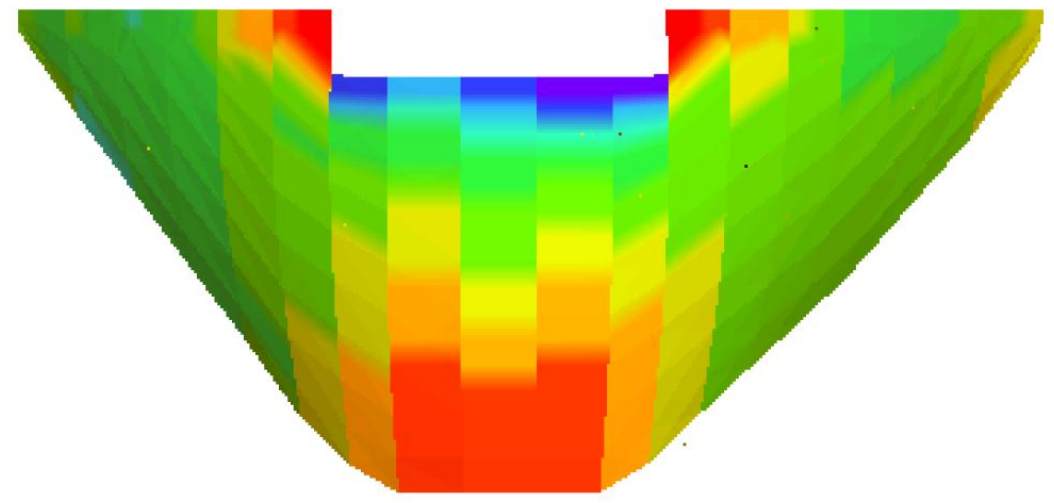

(b)

Figure 7. Envelope of peak arch compressive stresses, Foz Tua dam: (a) upstream face; (b) downstream face. 

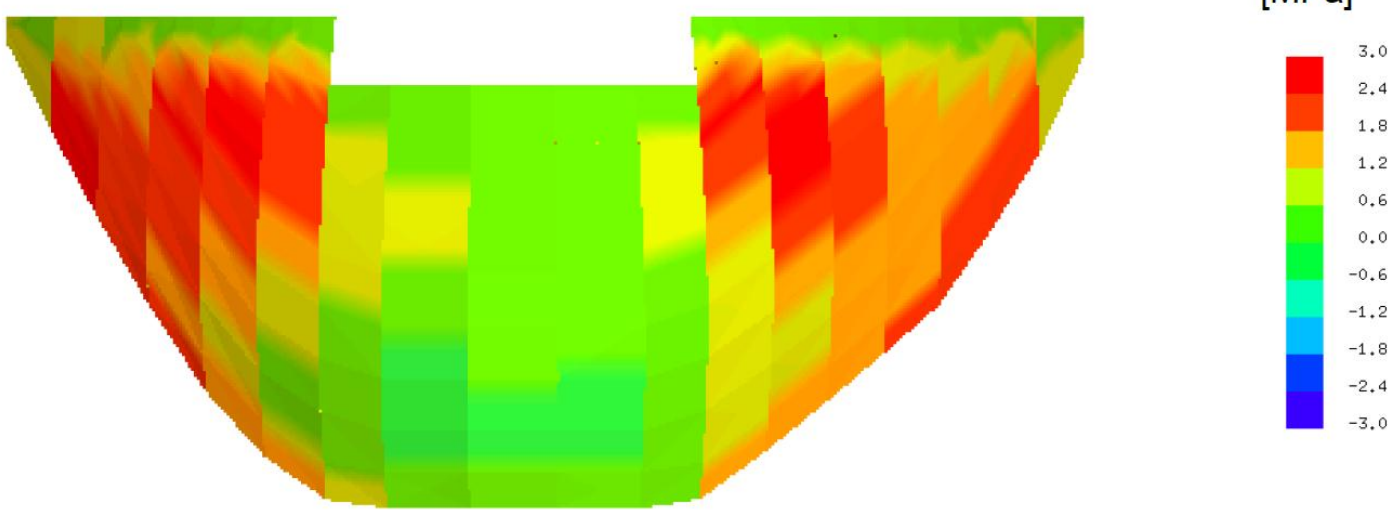

(a)

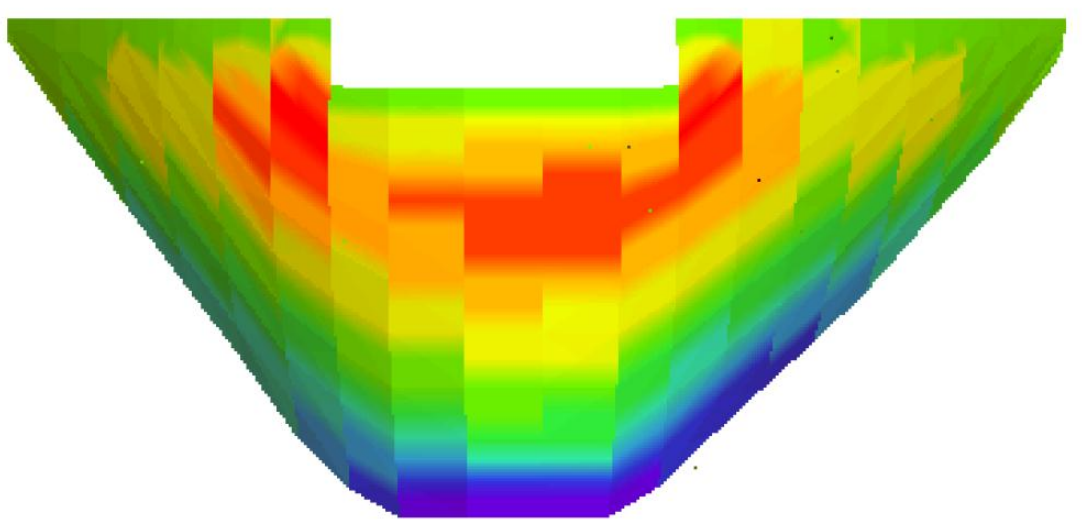

(b)

Figure 8. Envelope of peak cantilever tensile stresses, Foz Tua dam: (a) upstream face; (b) downstream face.

At the dam-rock interface, however, where stress concentrations are anticipated, the assumed $3 \mathrm{MPa}$ tensile limit was attained, so episodes of joint opening took place along the upstream edge of the joint, mainly in the central part of the valley. Fig. 9 shows the contours of peak separation, with a maximum of about $5 \mathrm{~mm}$. However, most of the dam-rock interface remained elastic, not permitting the development of shear slip.
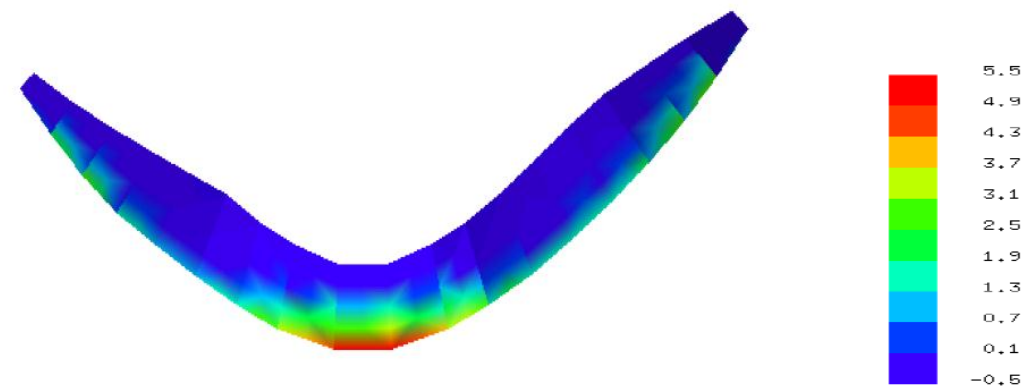

Figure 9. Contours of maximum opening at dam-rock interface, Foz Tua dam. 
In the vertical contraction joints, the episodes of joint separation were restricted to the uppermost arches, with a maximum opening under $2 \mathrm{~mm}$. Fig. 10 depicts the joint normal displacement in one of the joints in the spillway section, where essentially three short episodes of opening are visible. Form the analyses performed, it may be concluded that Foz Tua dam is capable of withstanding the action of the MDE with a substantial safety margin.

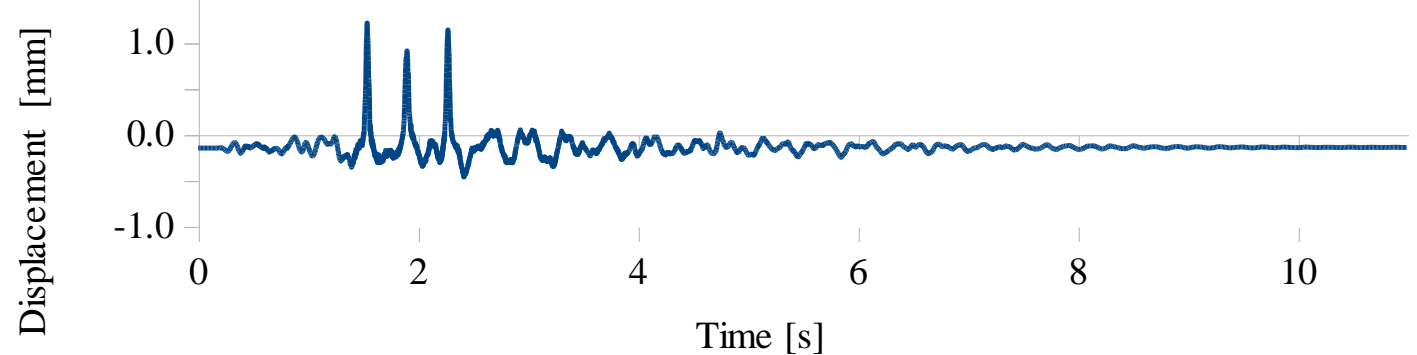

Figure 10. Normal relative displacement of contraction joint at the crest, Foz Tua dam.

\subsection{Analysis of results - Fridão dam}

Fridão dam has a lower height than Foz Tua, 98 m against 108 m, but lies in a wider valley, leading to a larger crest length, $300 \mathrm{~m}$ against $275 \mathrm{~m}$. Before the nonlinear dynamic analysis, modal analyses were undertaken with a massless foundation model using the same numerical meshes. For full reservoir conditions, the lowest asymmetric mode has a frequency of $2.9 \mathrm{~Hz}$, and the lowest symmetric mode of $3.1 \mathrm{~Hz}$ (Fig. 11).

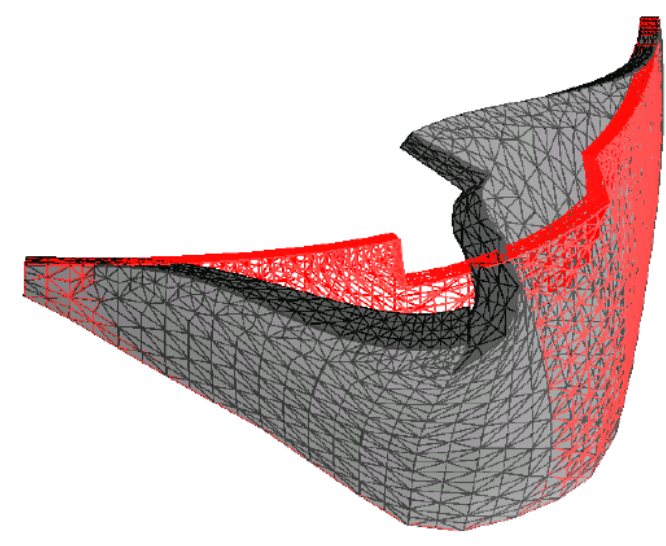

(a) mode $1(2.9 \mathrm{~Hz})$

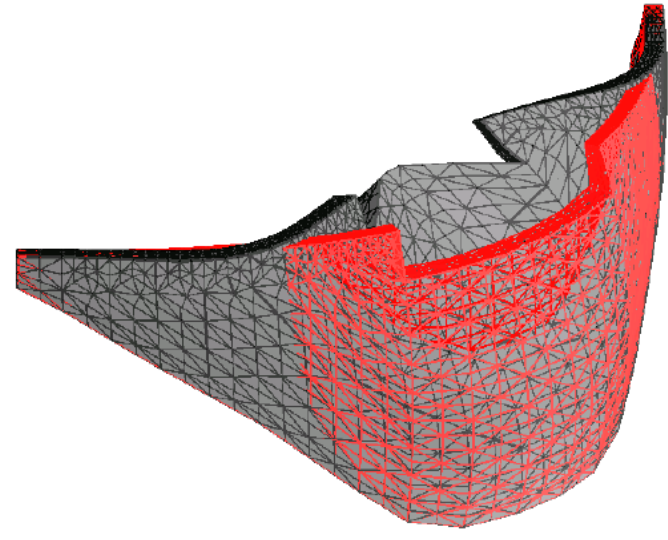

(b) mode $2(3.1 \mathrm{~Hz})$

Figure 11. Modal shapes for the two lowest frequencies, Fridão dam.

The seismological studies prescribed a less severe action at this site, leading to a PGA for the MDE of $0.14 \mathrm{~g}$ instead of $0.27 \mathrm{~g}$ for Foz Tua dam. The design of both dams being relatively similar, less important earthquake effects are to be expected. A 3DEC numerical model, similar to the one shown in Fig. 4, was built for the dynamic analysis of Fridão dam. The non- 
elastic behavior was again concentrated at the discontinuity surfaces, the dam-rock interface and the vertical contraction joints. As in the previous case, several analyses were performed with seismic records generated by the fault rupture model.

Fig. 12 displays the history of upstream-downstream displacement at the dam crest in one of the nonlinear analyses, with a peak value of about $38 \mathrm{~mm}$, approximately the double of the static displacement for the full reservoir condition. The peak stresses obtained for the various records were lower than those of Foz Tua dam. In the nonlinear case, for full reservoir water level, the peak compression in the arches ranged from 5.2 to $6.4 \mathrm{MPa}$. In the cantilevers, maximum compressive stresses between 4.4 to $5 \mathrm{MPa}$ were obtained, while the tensile stress peaks ranged from 0.9 to $1.5 \mathrm{MPa}$.

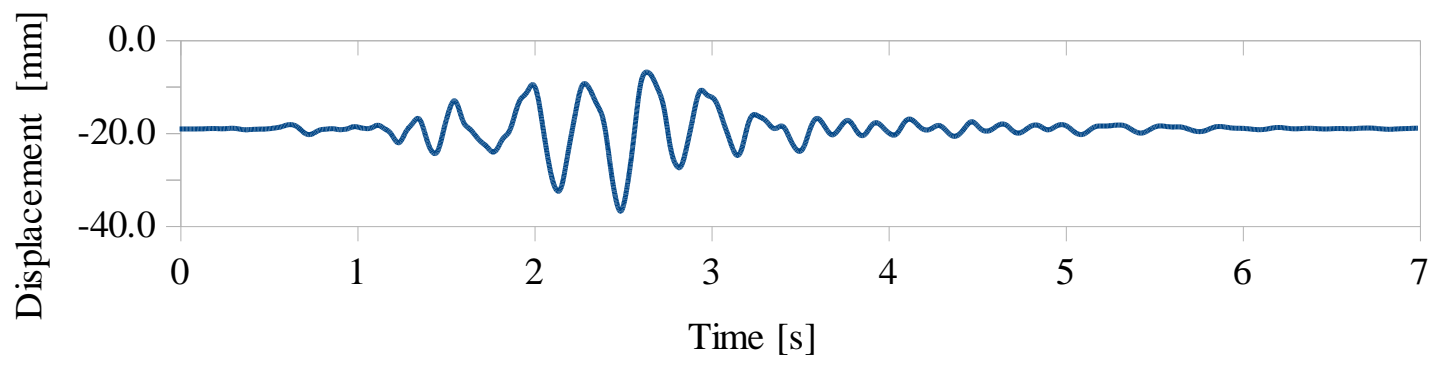

Figure 12. Horizontal displacement at crest, Fridão dam.

The discontinuity placed at the dam-rock interface showed small regions of tensile failure, at the upstream edge, as shown by the peak opening contours of Fig. 13, where the maximum value is $1.4 \mathrm{~mm}$. The contraction joints displayed few episodes of opening, the maximum value being $0.5 \mathrm{~mm}$. In conclusion, the MDE analyses confirm the seismic safety conditions of the dam.

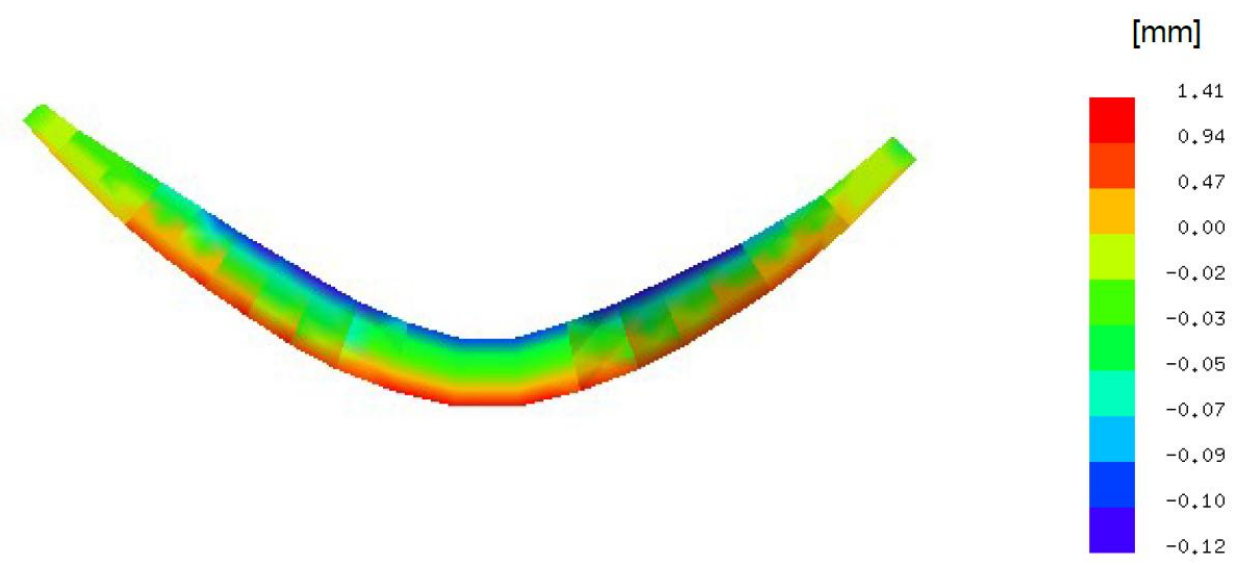

Figure 13. Contours of maximum opening at dam-rock interface, Fridão dam. 


\section{CONCLUSIONS}

The safety of large structures, such as arch dams, is always a major concern, namely in regions of significant seismic activity. Dynamic analysis in the time domain is an essential step in the verification of safety requirements, taking into account the expectable nonlinear behavior of materials or interfaces. The focus of the numerical model presented is on the nonlinear response of the various discontinuities surfaces, which may be the dam contraction joints or lift joints, the dam-rock interface or joints in the rock mass.

Two cases studies were presented, Foz Tua and Fridão dams, $108 \mathrm{~m}$ and $98 \mathrm{~m}$ high respectively. The model produced the predicted response for the Maximum Design Earthquake, taking into account the hydrodynamic effects, the opening of the contraction joints and the cracking of the dam-rock interface considering exploitation and failures scenarios. The analyses reported confirmed the full compliance of these designs with the safety requirements.

\section{REFERENCES}

[1] Lemos J.V., "Discrete element analysis of dam foundations", in Distinct Element Modelling in Geomechanics (eds. Sharma, Saxena \& Woods), Balkema, 89-115, 1999.

[2] Câmara R.C., "A method for coupled arch-dam-foundation-reservoir seismic behaviour analysis", Earthquake Engineering and Structural Dynamics, 29(4):441-460, 2000.

[3] EDP, Gestão da Produção de Energia, S. A., Foz Tua Hydroelectric Project - Design, 2010. (in Portuguese)

[4] EDP, Gestão da Produção de Energia, S. A., Fridão Hydroelectric Project - Design, 2011. (in Portuguese)

[5] Portuguese Regulations for Safety of Dams, Decreto Lei nº198 de 15 de Outubro, 2007. (in Portuguese)

[6] Portuguese Dam Design Recommendations (PDDR), Anexo à Portaria nº 846/93, 1993. (in Portuguese)

[7] ICOLD, Bulletin 72. Selecting Seismic Parameters for Large Dams, 1989.

[8] LNEC, Foz Tua Hydroelectric Project. Seismic studies. Characterization of the seismic action, Report 205/2010, LNEC, Lisbon, 2010. (in Portuguese)

[9] LNEC, Fridão Hydroelectric Project. Seismic studies. Characterization of the seismic action, Report 269/2009, LNEC, Lisbon, 2009. (in Portuguese)

[10] Itasca, 3DEC Three-Dimensional Distinct Element Code, Version 4.0, Itasca Consulting Group, Minneapolis, USA, 2006.

[11] LNEC, Analysis of the dynamic behaviour of Foz Tua dam for the Maximum Design Earthquake, Report 189/2010, LNEC, Lisbon, 2010. (in Portuguese)

[12] LNEC, Analysis of the dynamic behaviour of the main dam of Fridão Hydroelectric Project for the Maximum Design Earthquake, Report 140/2011, LNEC, Lisbon, 2011. (in Portuguese) 